\title{
The role of socialization in Knowledge management in virtual teams
}

\author{
Artemis Akhgar \\ Mehralborz University, Tehran, Iran \\ No.15, Second St., Gisha, \\ Tehran, Iran \\ artemisakhgar@gmail.com
}

\author{
Aryan Gholipour \\ School of Management, \\ University of Tehran, \\ Chamran Highway, Ghisha Bridge, \\ Tehran, Iran \\ agholipor@ut.ac.ir
}

\begin{abstract}
The literature shows that new Knowledge creation methods underline the importance of team networks as a pillar of Knowledge creation in modern Organizations. Sharing tacit Knowledge is one of the difficulties of virtual teams (VTs). This is due to knowledge social nature in tacit knowledge sharing, non-existence face to face interactions which will cause gradual and variable performance in virtual team. This research attempts to discover the key factors in socialization application for improving knowledge creation and Knowledge sharing problems in virtual teams. We have used quantitative methods, our findings indicates that there is a significant correlation between socialization, tactics and virtual teams.
\end{abstract}

Learning socialization content, socialization tactics, virtual teams, knowledge management, cultural facilitator factors.

\section{INTRODUCTION}

Virtual organizations are one of the latest strategies for responding to pace of information technology development (Larsen \& Mclnerney, 2002). Virtual organizations could properly respond to their requirements with high flexibility and appropriate speed due to their structure. Virtual teams (VTs) are the main core of virtual organization which is include knowledge workers (Wong, 2000). Sharing knowledge is one of the subjects which is impressed by such conditions. Some studies, have shown that uneven and slowed performance is likely to result when team members do not interact face-to-face (see e.g., Von Krogh, Ichijo, \& Nonaka, 2000). These unintended consequences stem partly from the social nature of knowledge. Thus, the main problem is providing such conditions through socialization and extend it to VTs to overcome the challenges of achieving VTs benefits such as knowledge creation and it's sharing particularly tacit knowledge.

Understanding how knowledge is created and penetrated in an organization and how employees use it, is the distinction between first and second generation of knowledge management. In fact the second generation of KM engaging knowledge process and life cycle in organizations and put learning organizations as main foundation of knowledge creation. How facilitate knowledge sharing in the best way is one of the management challenges in VTs. Organization efforts for changing into knowledge-based organization would be successful if there is required cultural characteristics for implementing KM (Knowledge Management) in organization. In fact, individuals especially newcomers, learn organizational culture through socialization.

As managing VTs is the implication of using communication strategies and project management techniques and also social processes, we try to explore how the knowledge creation capacity of VTs can be improved through appreciation of the role of socialization considering virtualiztion necessities.

\section{LITERATURE REVIEW}

Drucker (1995) predicted the rise of "knowledge workers" and its critical role in the strategic success of enterprise. He argued that "acquiring and applying knowledge will increasingly become the key competitive factor - for career and earning opportunities of individuals; for the performance, perhaps even the survival of the individual organization; [and] for an industry" (p.236). This increasing dependence upon human knowledge for organizational success is linked with a number of significant management challenges. Commonly 
remarked upon is the inherent difficulty of stimulating knowledge creation in workplaces which are increasingly fast-paced, innovation-focused, and often involved with ambiguous and complex tasks (see e.g., Mohrman, Cohen, \& Mohrman, 1995; Wooldridge \& Minsky, 2002). Teaming is one intervention popularly advocated to address the challenges of knowledge creation under dynamic condition (Mohrman et al., 1995) that today it seems virtual teams are increasingly implemented among team types. In virtual teams (VT), member work together toward a common goal regardless of geographic location. Communications occur largely via telecommunications rather than face-to-face contact; consequently, members are able to communicate unconstrained by physical location. A notable advantage of VTs is that they afford access to the talents of individuals previously inaccessible by virtue of distance (see e.g., Kirkman, Rosen, Gibson, Tesluck, \& McPherson, 2002; Lewis, 1998; Malhotra, Majchrzak, carman, \& Lott, 2001).

Bauer and Koszegi (2003) define VTs as a common activity in body of independent cooperation. These teams can be included different national and organizational culture. Individuals from different cultures communicate with each other in different manners and have different group behaviors (shin, 2004). Cultural diversity increasing complexity, conflict and ambiguity in communications and makes it difficult to manage these kinds of teams. Thus, cultural diversity may cause of decreasing real productivity in these teams.

Success of organization in executing each strategy including knowledge management depends on organization culture which support it. Organization efforts for changing into Knowledge-based organization would be successful if there is required cultural characteristics for implementing $\mathrm{KM}$ in the organization because creating and sharing knowledge effectively depends on supporting organization culture (Ahmed \& Wang, 2003). Thus we come to conclude that developing openness (Luthans,1998), sharing (Mc Dermott, 2001), trust (Lee \& Choi, 2003) and learning could play the main role in facilitating knowledge management.

Writing about entire organizations, Wooldridge and Minsky (2002) advocated a deliberate focus upon socialization as a means for addressing the challenge of achieving the coordination involved with knowledge creation goals.

As we know, humans are social consequently socialization is inseparable part of their social life. Their organizational and position community is one of the communities that they live in, in which socialization becomes applicable. Louis (1980) defined socialization as:
...The process by which an individual comes to appreciate the values, abilities, expected behaviors, and social knowledge essential for assuming an organizational role and for participating as an organization member. Regardless of an individual's previous socialization experience, each major passage or role change involves socialization into the new rile and setting ... organizational socialization is a pervasive process throughout adult life (p.230).

In socialization a process should be structured for employee adjustment to organization culture which including three following stages: (1) prearrival stage; (2) encounter stage; and (3) metamorphosis stage (Robbins,2011). Accomplishing socialization process successfully lead to get an undertaking by individuals, thus the productivity will increasing in organization otherwise the individual would leave the work.

Bauer and Green (1976;1981) modeled socialization as occurring in three stages, but suggested initial stages can also directly influence final accommodation of newcomers. They defined accommodation as " the process in which newcomers learn what the organization expects from them and learn to be participating members of their work group" (1994, p.213). Among outcome variables Bauer and Green selected those which past research has shown are related to socialization, including productivity, measured as number of publications and grant/publication submissions. Findings from the study supported the hypotheses that pre-entry variables, including realism and past experience, exert a direct and positive influence on outcome variables such as productivity.

Chao, O' Leary-Kelly, Wolf, Klein, and Gardner (1994) conducted research designs to identify what is learned through the socialization process, thus further refining stage models. The resulting framework included only those dimensions potentially under the influence of the organizational because, Chao and colleagues argued, socialization is largely "concerned with the organization's on an individual's learning" (1994, p.731). Through review of the literature they identified important learning dimensions including (1) performance proficiency: job task learning, (2) people: learning to establish satisfying and successful work relations, (3) politics: acquiring information regarding formal and informal work relations, (4) language: learning unique professional and organizational terminology, (5) organizational goals and values: including tacit goals and values, and (6) history: acquisition of 
knowledge regarding personal histories of peers, organizational traditions and so on.

While socialization occurs throughout careers, the early literature primarily addressed experiences of newcomers to an organization (see e.g., Jones, 1986; Van Maanen, 1975; Van Maanen \& Schein, 1979). Such entry tends to be characterized by encountered "surprise" brought upon by contrast between expectations and actual experience (Louis, 1980). New employees seek to alleviate the resultant anxiety and uncertainty through learning about their surroundings; learning which can be intentionally influenced through socialization or engaged upon in individual fashion (Jones, 1986).

Seeking to understand the manner in which socialization occurs, Van Maanen (1975) identified specific tactics in a study involving a sample of police recruits. He found that characteristics of the organizational environment (e.g., degree of formality) and tactics enacted (e.g., collective versus individual processing) influenced specific performance- related outcomes, including job attitudes and homogeneity of values.

Schein, detailing altogether seven socialization dimensions (Van Maanen \& Schein, 1979). Each represents a continuum between two labeled endpoints (e.g., collective-individual; sequentialrandom; investiture-divestiture; formal-informal; fixed-variable; serial-disjunctive). Studies tend to exclude the seventh dimension (tournamentcontest) with empirical work focusing upon the other six (Schein, 1990; Van Maanen \& Schein, 1979).

Socialization stage models suggest learning regarding specific domains (Chao et. al., 1994; Feldman, 1976; 1981), for example, colleagues, group politics, tasks will predict adjustment outcomes including trust and shared values. First hypothesis illustrate proposed associations between such variables:

Hypothesis 1: Socialization content learning will show a positive relationship with culture facilitator factors (openness, sharing, learning and trust culture).

Integrating findings from studies across disciplines, our hypothesis indicates that tacit knowledge sharing is facilitated when the social context characterized by openness, learning, sharing and trust. Furthure, previous research has shown a relationship between a number these same variables and specific socialization tactics. Adjustment which occurs through facilitated processes is termed institutionalized and tactics typically include collective, formal, sequential, fixed, serial, and divestiture endpoints on the continuum (see e.g., Jones, 1986).
Socialization can also proceed through an individual's own efforts. Tactics characteristic of this individualized configuration include individual, informal, variable, random, fixed, disjunctive, and divestiture points on socialization dimensions. In prior research, this pattern has shown a negative association with relational variables like trust (Ashforth \& Saks, 1996; Baker \& Feldman, 1991). Such findings suggest:

Hypothesis 2: Institutionalized socialization will positively relate to culture facilitator factors (openness, sharing, learning and trust culture).

Prior study shows that socialization learning and subsequent adjustment also might be realized in instances where newcomers or role-changes exhibit proactive behaviors (Marrone \& Taylor, 2004). Either because of prior experience or individual differences, research indicates that some newcomers display more proactive dispositions toward relationship-building with new colleagues (Marrone \& Taylor, 2004). Through proactive means they may acquire important information regarding colleagues, politics and so on in the absence of purposeful managerial intervention (Beyer \& Hannah, 2002; McGrath \& Berdhal, 1998). Such findings suggest the following relationships between individual socialization behaviors and outcomes of interest:

Hypothesis 3: Team member proactive behaviors will show a positive relationship with culture facilitator factors (openness, sharing, learning and trust culture).

Ashforth, Saks, and Lee (1998) argued that the organizational context within which socialization experiences occur may influence the effectiveness of adopted practices. Newcomers to more complex environments encounter greater challenges in adjusting. Notably, previously reviewed studies demonstrate variation across VTs in terms of team complexity (international, functional, and disciplinary diversity, greater distances between members and so on). Complex team designs are more likely to be associated with uneven member relationships and difficulty in achieving important performance-related outcomes like mutual knowledge (Cramton, 2001). Taken together, these observations suggest that the adjustment of team newcomers will be influenced by the complexity of the context in which it occurs. Posited implication include:

Hypothesis 4: Team complexity will be negatively associated with culture facilitator factors (openness, sharing, learning and trust culture). 


\section{RESEARCH METHODOLOGY}

The purpose of this research is to extent the applicable knowledge in socialization and knowledge management and has been done to apply its findings for solving challenges of virtual teams. This practical field study is descriptive survey looking for a causative relation between the variables.

This study is conducted a standard questionnairebased survey of VTs from Tehran University to present the relationship between socialization and $\mathrm{KM}$. The sample is selected randomly and questionnaires were distributed among $104 \mathrm{VT}$ members of sample out of 35 VTs. 104 usable responses were received.

\section{FINDINGS}

For analyzing hypothesis 1, SPSS results show that: Pearson correlation coefficient between learning socialization content and trust is 0.408 . The significant number is lower than 0.01 and is 0.000 (sig. <0.01) which is lower than standard level of significance. So, there is a positive significant relation between these variables in \%99 confidence level.

Pearson correlation coefficient for between learning socialization content and openness is 0.233 . The significant number is lower than 0.05 and is 0.017 (sig. <0.05) which is lower than standard level of significance. So, there is a positive significant relation between these variables in $\% 95$ confidence level.

Pearson correlation coefficient for between learning socialization content and sharing is 0.317 . The significant number is lower than 0.01 and is 0.001 (sig. <0.01) which is lower than standard level of significance. So, there is a positive significant relation between these variables in \%99 confidence level.

Pearson correlation coefficient for between learning socialization content and learning culture is 0.581 . The significant number is lower than 0.01 and is 0.000 (sig. <0.01) which is lower than standard level of significance. So, there is a positive significant relation between these variables in \%99 confidence level.

For analyzing hypothesis 2, SPSS results show that there is a significant correlation between trust and SD tactic (0.433); ID tactic (0.495); FV tactic (0.408); FI tactic (0.241). There is a significant correlation between openness and SD tactic (0.625); ID tactic (0.554); FV tactic (0.399); FI tactic (0.212); SR tactic (0.344); Cl tactic $(0.369)$. There is a significant correlation between sharing and SD tactic (0.484); ID tactic (0.700); FV tactic (0.484); SR tactic (0.222); Cl tactic (0.463). There is a significant correlation between learning and SD tactic (0.503); ID tactic (0.465); FV tactic (0.462); FI tactic (0.346); SR tactic (0.316); Cl tactic (0.200).

For analyzing hypothesis 3 Pearson correlation coefficient for between team member proactive behaviors and culture facilitator factors is 0.468 . The significant number is lower than 0.01 and is 0.000 (sig. <0.01) which is lower than standard level of significance. So, there is a positive significant relation between these variables in \%99 confidence level.

For analyzing hypothesis 4 Pearson correlation coefficient for between team complexity and culture facilitator factors is -0.257 . The significant number is lower than 0.01 and is 0.009 (sig. $<0.01$ ) which is lower than standard level of significance. So, there is a negative significant relation between these variables in \%99 confidence level.

\section{DISCUSSION AND CONCLUSION}

The culture facilitator factors suggests practical approaches to facilitating sharing of the tacit domain in VTs - valuable contributions assuming teams are engaged in knowledge creation.

While other researchers have acknowledged the role of the tacit in achieving VT effectiveness, the manner in which its sharing might be supported and achieved has tended to remain elusive. This study also suggests solutions to the problems limiting tacit knowledge sharing in VTs. The literature describes and promotes the integral role of socialization in general for realized sharing of the tacit. Results here identify specific tactics which relate to desired cultural facilitator factors defined by trust, openness, learning and sharing.

Results of this study suggest that successful learning of specific content areas relevant to the team (e.g. politics, goals \& values) associate with the cultural facilitator factors. Proactive behaviors were shown to positively associate with the culture facilitator factors variables. This finding implies the potential for greater levels of performance in knowledge-creating teams whose members tend toward pro-activity. These observations suggest possible selection criteria that could guide the team development process. In detailing essential processes and demonstrating links between those processes, learning, and desirable outcomes, this study lays the foundation for continued and important future research. The agenda suggested by findings is ambitious. However, knowledge generation is notably an increasingly critical 
performance issue for success in the global economy. Consequently, research that offers solutions for facilitating and supporting its creation seems particularly urgent. VTs provide a valuable microcosm for assessing both the knowledge creation advantages and limitations of global relationships in an increasingly virtual world.

\section{REFERENCES}

Ashforth, B. E.,\&Saks, A. M. 1996. Socialization tactics: Longitudinal effects on newcomer adjustment. Academy of Management Journal, 39(1): 149-178.

Bauer, T. N. \& Green, S. G. (1994). Effect of newcomer involvement in work-related activities: A longitudinal study of socializtion. Journal of Applied Psychology, 79, 211-233.

Beyer, J. M. \& Hannah, D. R. (2002). Building on the past: Enacting established personal identities in a new work setting. Organization Science, 13, 636652.

Chao. G. T., O' Leary-Kelley, A. M., Wolf, S., Klein, H., \& Gardner, P. (1994). Organizational socialization: Its content and consequences. Journal of Applied Psychology, 79, 730-743.

Cramton, C. D. (2001). The mutual knowledge problem and is consequences for dispersed collaboration. Organizational Science, 12, 346-371.

Drucker, P. (1995). Managing in a Time of Great Change. New york: Truman Talley Books/Dutton.

Feldman, D. C. (1976). A contingency theory of socialization. Administrative Science Quarterly, 21, 433-452.

Feldman, D. C. (1981). The multiple socialization of organization members. The Academy of Management Review, 6, 309-318.

Jones, G. R. (1986). Socialization tactics, selfefficacy, and newcomers' adjustment to organization. The Academy of Management Journal, 29, 262-279.

Kirkman, B. L, Rosen, B., Gibson, C. B., Tesluck, P. E., \& McPherson, S. O. (2002). Five challenges to virtual team success: lessons from Sabre, Inc. The Academy of Management Executive, 16, 6779.

Larsern. Kai R.T, Mclnernrey. Claire R, 2002, Preparing to Work in the virtual organization, Information \&Management, 39 . 445-456.
Lee , R. and Choi, B (2003). "Knowledge management enablers, processes, and organizational performance: An integrarive view and empirical examinarion", J. Manage. Inf. Sys., 20(1).

Lewis, R. (1998). Membership and management of a virtual team: the perspective of a research manager. R\&D Management, 28, 5-12.

Louis, M. R. (1980). Surprise and sense making: What newcomers experience in entering unfamiliar organizational settings. Administrative Science Quarterly, 25, 226-251.

Malhotra, A., Majchrzak, A., Carman, R., \& Lott, V. (2001). Radical innovation without collocation: A case study at Boeing-Rocketdyne. MIS Quarterly, 25, 229-249.

Marrone, J. A. \& Taylor, M. S. (2004, April). Undrestanding change during newcomer socialization: A proposed theoretical model of newcomer proactive behavior and proximal socialization outcomes. Paper presented at annual conference of the Society for Industrial and Organization Psychology, chicago, IL.

McDermott, R. (2000). Why information technology inspired but cannot deliver Knowledge management. In E. L. Lesser, M. A. Fontaine, \& J. A. Slusher (Eds.), Knowledge and Communities (pp. 21-35), Boston, MA: Betterworth-Heinemann.

McGrath, J. E. \& Berdahl, J. L. (1998). Groups, technology, and time: Use of computers for collaborative work. In R. S. Tindale, L. Heath, J. Edwards, E. J. Posavac, F. B. Bryant, Y. SuarezBalcazar, E. Henderson-King, \& J. Myers (Ed.), Theory and Research on Small Groups (pp. 205228). New York and London: Plenum Press.

Mohrman, S. A., Cohen, S. G., \& Mohrman, A. M. (1995). Designing Team-based Organization: New Forms for Knowledge Work. San Francisco: Jossey-Bass Publishers.

Saarenket S, Puumalainen K, Kuivalainen 0 , Kylaheiko K (2003). "Dynamic knowledge-related learning processes in internationalizing high-tech SMEs", International Journal of Production Economics, in Press, Corrected Proof, [Online], accessed, 10 November, 2004.

Shin.Yuhyng, 2004, A person-Environment fit model for virtual organization, Journal of Management 30(5), 725-743.

Van Maanen, J. (1975). Police socialization: A longitudinal examination of job attitudes in an urban 
police department. Administrative Science Quarterly, 20(2), 207-228.

Van Maanen, J., \& Schein, E. H. (1979). Toward a theory of organizational socialization. In B. M. Shaw (Ed.), Research in Organizational Behavior (pp. 209-264), Greenwich, CT: JAI Press.

Von Krogh, G. Ichijo, K. \& Nonaka, I. (2000). Enabling Knowledge Creation. Oxford: Oxford University Press.

Wang Catherine L., Ahmed Perveiz, K., Structure \& Structural Dimensions For Knowledge- Based
Organizations, Measuring Business Excellence, Vol7, Issue 1:12.

Wong. S, Burton. R.M, 2000, Virtual team: What are their characteristics, and impact on team performance?, Computational \& Mathematical Organization Theory ,6 (4), 339-360.

Wooldridge, B. R. \& Minsky, B. D. (2002). The role of climate and socialization in developing interfuctional coordination. The Learning Organization, 9, 29-38. 